\title{
PENGARUH MUTU PELAYANAN KESEHATAN GIGI DAN MULUT TERHADAP KUNJUNGAN PASIEN DI PUSKESMAS DARUSSALAM KECAMATAN MEDAN PETISAH MEDAN TAHUN 2015
}

\author{
Ngena Ria \\ Jurusan Keperawatan Gigi Poltekkes Kemenkes Medan
}

\begin{abstract}
Abstrak
Peningkatan mutu pelayanan kesehatan akan menjadi tuntutan masyarakat terutama dengan semakin meningkatnya pendidikan dan sosial ekonomi. Masyarakat sebagai pengguna jasa pelayanan kesehatan selalu menginginkan pelayanan yang diterima sesuai dengan harapan, sehingga dapat memberikan kepuasan bagi penerima layanan kesehatan. Kepuasan pasien yang dihasilkan dari pelayanan Puskesmas tidak terlepas dari pelayanan tenaga medis (dokter) yang memberikan pelayanan. Tujuan penelitian ini adalah untuk mengetahui sejauh mana mutu pelayanan kesehatan gigi dan mulut di Puskesmas Darussalam dan perbedaan kepuasan pasien yang telah berkunjung dan kembali berkunjung dengan pasien yang telah berkunjung dan tidak kembali berkunjung. Rancangan penelitian adalah penelitian analitik dengan pendekatan cross sectional. Besar sampel 30 orang pasien yang pernah berkunjung dan kembali berkunjung dan 30 orang pasien yang pernah berkunjung dan tidak kembali berkunjung. Pengumpulan data menggunakan kuesioner yang diberikan secara langsung kepada pasien setelah menerima tindakan perawatan gigi. Kepuasan pasien di ukur dari dimensi empati, dimensi fisik, dimensi jaminan dan dimensi ketanggapan. Analisis dilakukan secara manual untuk melihat perbedaan kepuasan pasien yang berkunjung ke poli gigi Puskesmas Darussalam. Karakteristik pasien yang berkunjung ke poli gigi Puskesmas Darussalam kebanyakan perempuan, berumur 17-27 tahun. Pasien yang datang berkunjung ke poli gigi Puskesmas Darussalam mempunyai peluang untuk puas terhadap pelayanan kesehatan gigi dan mulut. Disarankan kepada Puskesmas Darussalam Medan, Puskesmas maupun profesi dokter gigi untuk meningkatkan mutu pelayanan kesehatan gigi dan mulut dengan memperhatikan dimensi-dimensi yang dapat mempengaruhi mutu peayanan kesehatan gigi dan mulut yang berpengaruh terhadap kunjungan pasien di poli gigi Puskesmas Darussalam.
\end{abstract}

Kata kunci : Mutu Pelayanan, Kunjungan Pasien

\section{Latar Belakang}

Kesehatan merupakan salah satu unsur yang sangat penting dari mutu kehidupan dalam pembangunan nasional untuk mewujudkan manusia Indonesia seutuhnya. Pembangunan kesehatan bertujuan untuk memberikan kesempatan yang seluas-luasnya bagi masyarakat untuk memperoleh derajat kesehatan yang optimal hal ini dapat diwujudkan antara lain dengan membangun Puskesmas di seluruh Indonesia yang dinyatakan dalam Undang Undang Kesehatan No.23 tahun 1992.

Kesehatan gigi dan mulut bertujuan untuk menurunkan secara bermakna insidens dan prevalensi penyakit gigi dan mulut, sehingga tidak menjadi masalah kesehatan masyarakat demi tercapainya derajat kesehatan gigi masyarakat yang optimal (DepKes RI, 2003).

Departemen Kesehatan RI melaporkan dari Hasil Survei Kesehatan Rumah Tangga 2001 bahwa secara umum diantara penyakit yang dikeluhkan, prevalensi penyakit gigi dan mulut adalah yang tertinggi meliputi $60 \%$ penduduk. Hasil penelitian Situmorang, N (2003) yang dilakukan di dua kecamatan di Kota Medan, menunjukkan bahwa penyakit karies gigi dapat mempengaruhi kualitas hidup manusia. Dampak penyakit karies gigi memerlukan perhatian secara menyeluruh dalam upaya meningkatkan kualitas hidup masyarakat Indonesia. Selain itu dari hasil penelitian diperoleh prevalensi karies gigi di dua kecamatan $90 \%$, tetapi hanya $10 \%$, responden yang pernah berobat ke pelayanan kesehatan. Dari hasil tersebut terlihat bahwa kebutuhan masyarakat (need) terhadap kesehatan gigi sebenarnya tinggi, tetapi permintaan (demand) masih rendah.

Hal ini lebih terlihat lagi dari rendahnya jumlah pengunjung yang memanfaatkan jasa pelayanan di Puskesmas. Tingkat pemanfaatan fasilitas pelayanan kesehatan di Puskesmas oleh pasien menunjukkan seberapa baik mutu pelayanan kesehatan yang diberikan oleh petugas pelayanan Puskesmas sekaligus menunjukkan tingkat kepercayaan pasien terhadap penyelenggaraan pelayanan kesehatan di Puskesmas. Secara umum, pengukuran tingkat pemanfaatan fasilitas pelayanan kesehatan ditunjukkan dengan jumlah kunjungan pasien ke fasilitas pelayanan kesehatan tersebut.

Puskesmas merupakan ujung tombak pelaksanaan pelayanan kesehatan di suatu daerah di 
Indonesia dan merupakan organisasi yang bersifat menyeluruh dan terpadu yang paling dekat dengan masyarakat. Pelayanan masyarakat meliputi upaya peningkatan, pencegahan dan penyembuhan. Peran dan fungsi Puskesmas sangat strategis dalam pembangunan kesehatan di Indonesia. Puskesmas berperan menyelenggarakan upaya kesehatan untuk meningkatkan kesadaran, kemauan, dan kemampuan hidup sehat bagi setiap penduduk agar memperoleh derajat kesehatan yang optimal.

Mutu pelayanan kesehatan ditunjukkan pada tingkat kesempurnaan pelayanan kesehatan melalui harapan pasien dan kinerja layanan kesehatan yang dirasakan sewaktu menggunakan layanan. Hal ini dapat dilihat dari dimensi empati (empathy), dimensi tampilan fisik (tangible), dimensi jaminan (assurance), dan dimensi ketanggapan (responsiveness) yang sangat berpengaruh terhadap kunjungan.

Perbedaan kunjungan pelayanan secara umum diduga disebabkan oleh mutu pelayanan kesehatan di Puskesmas, artinya semakin baik mutu pelayanan maka semakin tinggi frekuensi kunjungan.

Adanya asumsi tersebut maka peneliti tertarik untuk melakukan penelitian dengan judul "Pengaruh Mutu Pelayanan Kesehatan Gigi dan Mulut Terhadap Kunjungan Pasien Di Puskesmas Darussalam Jl.Darussalam No.40 Medan".

\section{Rumusan Masalah}

Berdasarkan uraian pada latar belakang diatas, maka dapat dirumuskan masalah penelitian sebagai berikut: " Bagaimana Pengaruh Mutu Pelayanan Kesehatan Gigi dan Mulut Terhadap Kunjungan Pasien di Puskesmas Darussalam Jl.Darussalam No.40 Medan”.

\section{Tujuan umum}

Tujuan umum dari penelitian ini adalah untuk mengetahui pengaruh mutu pelayanan kesehatan gigi dan mulut terhadap kunjungan pasien di Puskesmas Darussalam Jl. Darussalam no. 40 Medan.

\section{Tujuan khusus}

Tujuan khusus dari penelitian ini adalah :

1. Untuk mengetahui pengaruh mutu pelayanan kesehatan gigi dan mulut yang dilihat dari dimensi empati (empathy).

2. Untuk mengetahui pengaruh mutu pelayanan kesehatan gigi dan mulut yang dilihat dari dimensi tampilan fisik (tangible).

3. Untuk mengetahui pengaruh mutu pelayanan kesehatan gigi dan mulut yang dilihat dari dimensi jaminan (assurance).

4. Untuk mengetahui pengaruh mutu pelayanan kesehatan gigi dan mulut yang dilihat dari dimensi ketanggapan (responsiveness).

5. Untuk mengetahui pengaruh mutu pelayanan terhadap kunjungan pasien di Puskesmas Darussalam.

\section{Manfaat Penelitian}

Hasil penelitian ini diharapkan memberikan manfaat sebagai berikut:
1. Sebagai masukan bagi Puskesmas di wilayah kerja dinas kesehatan Kota Medan dalam peningkatan mutu pelayanan kesehatan dasar khususnya pelayanan kesehatan gigi dan mulut.

2. Sebagai masukan kepada profesi dokter gigi dalam pengembangan pelayanan kesehatan gigi dan mulut.

3. Diharapkan dapat mengembangkan ilmu pengetahuan bagi para peneliti yang akan datang.

\section{Hipotesis \\ Hipotesis Kerja (Alternatif = Ha)}

Hipotesis kerja (Ha) menyatakan adanya hubungan antara 2 variabel atau lebih atau adanya perbedaan ciri-ciri dua kelompok populasi yang akan diteliti.

$\mathrm{Ha}=$ Adanya pengaruh mutu pelayanan kesehatan gigi dan mulut terhadap kunjungan pasien di Puskesmas Darussalam.

\section{Hipotesis NOL}

Hipotesis nol menyatakan tidak ada perbedaan antara dua variabel atau tidak ada pengaruh variabel $\mathrm{X}$ terhadap variabel Y.

Tidak ada pengaruh mutu terhadap kunjungan.

\section{Jenis dan Desain Penelitian}

Jenis penelitian yang dipakai pada penelitian ini adalah penelitian analitik dengan metode cross sectional yaitu untuk mengetahui "Pengaruh Mutu Pelayanan Kesehatan Gigi Dan Mulut Terhadap Kunjungan Pasien Di Puskesmas Darussalam Jl. Darussalam No.40 Medan.

\section{Lokasi Penelitian}

Penelitian ini dilakukan di Puskesmas Darussalam Jl. Darussalam No.40 Medan dengan alasan ingin mengetahui pengaruh mutu pelayanan kesehatan gigi dan mulut terhadap kunjungan pasien di Puskesmas Darussalam.

\section{Populasi Penelitian}

Populasi adalah keseluruhan objek penelitian yang diteliti. Populasi dalam penelitian ini adalah pasien yang datang berkunjung di poli gigi Puskesmas Darussalam.

\section{Sampel Penelitian}

Cara pengambilan sampel:

1. Pasien yang pernah berkunjung sebelumnya dan kembali lagi berkunjung ke poli gigi Puskesmas Darussalam.

2. Pasien yang pernah berkunjung sebelumnya dan tidak kembali lagi berkunjung ke poli gigi Puskesmas Darussalam.

3. Teknik sampling yang digunakan yakni purposive sampling.

4. Pasien usia $>17$ tahun.

5. Berdasarkan data sekunder dari Puskesmas pada bulan April 2015, jumlah pasien yang berkunjung dalam seminggu ialah 30 orang dengan jumlah kunjungan 515 orang perhari. Oleh karena itu maka sampel diambil 
berdasarkan rata-rata kunjungan minimal sehari dari seluruh sampel.

\section{Jenis Dan Cara Pengumpulan Data} berikut :

Pengumpulan data dilakukan dengan cara sebagai

\section{- Data sekunder}

Data sekunder ialah data yang diperoleh dengan melakukan observasi terhadap mutu pelayanan kesehatan gigi dan mulut yang berpengaruh terhadap kunjungan pasien di Puskesmas Darussalam.

\section{- Data primer}

Data primer ialah data kepuasan pasien terhadap pelayanan kesehatan gigi dan mulut yang diperoleh dengan melakukan pengambilan jumlah sampel yang kemudian memberikan kuesioner sebagai berikut:

1. Untuk dimensi empati (empathy) terdiri dari 10 pertanyaan:

a. Menerima dan menyapa dengan ramah

b. Mempunyai waktu untuk menanyakan keluhan

c. Memperhatikan keluhan

d. Ekspresi wajah yang lembut

e. Tutur sapa yang sopan

f. Menggunakan bahasa yang baik dan dimengerti

g. Memberitahukan hasil pemeriksaan gigi dengan jelas

h. Memberitahukan tindakan perawatan

i. Memberikan nasehat dari perawatan yang telah dilakukan

j. Memberikan saran dari perawatan yang telah dilakukan

2. Untuk dimensi tampilan fisik (tangible) terdiri dari 10 pertanyaan:

a. Kebersihan ruang tunggu

b. Kebersihan ruang perawatan

c. Kerapian ruang tunggu

d. Kerapian ruang perawatan

e. Kebersihan alat untuk tindakan perawatan

f. Kondisi alat baik

g. Alat untuk tindakan perawatan tersedia dan lengkap

h. Alat tersusun rapi

i. Kecanggihan alat untuk tindakan perawatan

j. Kenyamanan di ruang perawatan

3. Untuk dimensi jaminan (assurance) terdiri dari 10 pertanyaan :

a. Memberikan rasa aman

b. Bebas dari keraguan

c. Bebas dari masalah

d. Bebas dari resiko

e. Percaya atas tindakan yang dilakukan sesuai kebutuhan perawatan

f. Memberikan pelayanan secara menyeluruh dan tuntas

g. Memenuhi pelayanan yang dijanjikan

h. Puas terhadap pelayanan

i. Menjamin hasil yang baik

j. Kepastian akan kesembuhan pasien atas tindakan perawatan
4. Untuk dimensi ketanggapan (responsiveness) terdiri dari 10 pertanyaan :

a. Memeriksa dengan teliti

b. Bekerja cepat

c. Bekerja dengan tepat

d. Bekerja dengan aman

e. Hasil kerja / perawatan memuaskan

f. Terampil menggunakan alat

g. Terampil menenangkan pasien

h. Terampil mengajak pasien untuk mau dilakukan tindakan perawatan

i. Cepat memberikan obat bila diperlukan

j. Memberikan saran yang tepat.

\section{Pengolahan Dan Analisa Data}

Setelah data dikumpulkan, dilakukan analisis bivariat dengan uji chi square untuk melihat mutu pelayanan kesehatan gigi dan mulut yang mempengaruhi kunjungan pasien di poli gigi Pukesmas Darussalam.

\section{Hasil penelitian}

Dari hasil penelitian terhadap 60 pasien sebagai responden yaitu 30 pasien yang pernah berkunjung dan kembali berkunjung dan 30 pasien yang pernah berkunjung dan tidak kembali berkunjung diperoleh data sebagai berikut:

Tabel 2: Persentase Karakteristik Pasien Yang Pernah Berkunjung Ke Poli Gigi Puskesmas Darussalam Medan

\begin{tabular}{|c|c|c|c|c|c|}
\hline \multirow{2}{*}{ No } & \multirow{2}{*}{$\begin{array}{c}\text { Karakteristik } \\
\text { responden }\end{array}$} & \multicolumn{2}{|c|}{$\begin{array}{c}\text { Pasien yang pernah } \\
\text { berkunjung dan kembali }\end{array}$} & \multicolumn{2}{|c|}{$\begin{array}{l}\text { Pasien yang pernah } \\
\text { berkunjung dan } \\
\text { tidak kembali }\end{array}$} \\
\hline & & $\begin{array}{l}\text { Jum lah } \\
\text { (n) }\end{array}$ & $\begin{array}{l}\text { Persen- } \\
\text { tase } \\
(\%)\end{array}$ & $\begin{array}{l}\text { Jum lah } \\
\text { (n) }\end{array}$ & $\begin{array}{c}\text { Persen } \\
\text { tase } \\
(\%)\end{array}$ \\
\hline \multirow[t]{5}{*}{1} & Umur & & & & \\
\hline & - 17-27 tahun & 13 & 43,3 & 12 & 40 \\
\hline & $-28-38$ tahun & 9 & 30 & 9 & 30 \\
\hline & - 39- 49 tahun & 6 & 20 & 7 & 23,3 \\
\hline & $->50$ tahun & 2 & 6,6 & 2 & 6,6 \\
\hline \multirow[t]{3}{*}{2} & Jenis kelamin & & & & \\
\hline & - Laki-laki & 11 & 36,6 & 9 & 30 \\
\hline & - Perempuan & 19 & 63,3 & 21 & 70 \\
\hline
\end{tabular}

Karakteristik pasien yang menerima pelayanan kesehatan gigi dan mulut dapat dilihat dari umur dan jenis kelamin. Pada penelitian ini umur pasien terendah 17 tahun dan tertinggi 56 tahun. Persentase tertinggi kelompok umur 17-27 tahun. Pasien yang pernah berkunjung dan kembali berkunjung dan pasien yang pernah berkunjung dan tidak kembali berkunjung ke poli gigi Puskesmas Darussalam lebih banyak perempuan dibanding laki-laki yaitu 63,6\% dan $36,6 \%, 70 \%$ dan $30 \%$. 
Tabel 3 : Persentase Kepuasan Pasien Terhadap Pelayanan Kesehatan Gigi dan Mulut di Poli Gigi Puskesmas Darussalam Medan

\begin{tabular}{|c|c|c|}
\hline Variabel & $\begin{array}{l}\text { Pasien yg pernah } \\
\text { berkunjung\&ke } \\
\text { mbali }\end{array}$ & $\begin{array}{l}\text { Pasien yang } \\
\text { pernah } \\
\text { berkunjung dan }\end{array}$ \\
\hline
\end{tabular}

\begin{tabular}{|c|c|c|c|c|}
\hline & $\begin{array}{l}\text { Jum lah } \\
\text { (n) }\end{array}$ & $\begin{array}{c}\text { Persen } \\
\text { tase } \\
(\%)\end{array}$ & $\begin{array}{c}\text { Jum lah } \\
\text { (n) }\end{array}$ & $\begin{array}{c}\text { Persent } \\
\text { ase } \\
(\%)\end{array}$ \\
\hline \multicolumn{5}{|l|}{ Dimensi empati } \\
\hline $\begin{array}{l}\text { a. Menerima dan menyapa dengan } \\
\text { ramah }\end{array}$ & 17 & 56,6 & 1 & 3,3 \\
\hline $\begin{array}{l}\text { b. Mempunyai waktu untuk } \\
\text { menanyakan keluhan. }\end{array}$ & 30 & 100 & 24 & 80 \\
\hline c. Memperhatikan keluhan. & 30 & 100 & 26 & 86,6 \\
\hline d. Ekspresi wajah yang lembut & 29 & 96,6 & 11 & 36,6 \\
\hline e. Tutur sapa yang sopan & 30 & 100 & 19 & 63,3 \\
\hline $\begin{array}{l}\text { f. Menggunakan bahasa yang baik dan } \\
\text { dimengerti }\end{array}$ & 30 & 100 & 16 & 53,3 \\
\hline $\begin{array}{l}\text { g. Memberitahukan hasil pemeriksaan } \\
\text { gigi dengan jelas }\end{array}$ & 30 & 100 & 22 & 73,3 \\
\hline $\begin{array}{l}\text { h. Memberitahukan tindakan } \\
\text { perawatan }\end{array}$ & 30 & 100 & 24 & 80 \\
\hline $\begin{array}{l}\text { i. Memberikan nasehat dari } \\
\text { perawatan yang telah dilakukan }\end{array}$ & 29 & 96,6 & 20 & 66,6 \\
\hline $\begin{array}{l}\text { j. Memberikan saran dari perawatan } \\
\text { yang telah dilakukan }\end{array}$ & 28 & 93,3 & 28 & 93,3 \\
\hline
\end{tabular}

Dimensi fisik

a. Kebersihan ruang tunggu

b. Kebersihan ruang perawatan

c. Kerapian ruang tunggu

d. Kerapian ruang perawatan

e. Kebersihan alat untuk tindakan perawatan

f. Kondisi alat baik

g. Alat untuk tindakan perawatan tersedia dan lengkap

h. Alat tersusun rapi

i. Kecanggihan alat untuk tindakan perawatan

j. Kenyamanan di ruang perawatan

Dimensi jaminan

a. Memberikan rasa aman

b. Bebas dari keraguan

c. Bebas dari masalah

d. Bebas dari resiko

e. Percaya atas tindakan yang

dilakukan sesuai kebutuhan perawatan

f. Memberikan pelayanan secara menyeluruh dan tuntas

g. Memenuhi pelayanan yang dijanjikan

h. Puas terhadap pelayanan

i. Menjamin hasil yang baik

j. Kepastian akan kesembuhan pasien atas tindakan perawatan

Dimensi ketanggapan

a. Memeriksa dengan teliti

b. Bekerja cepat

c. Bekerja dengan tepat

d. Bekerja dengan aman

e. Hasil kerja / perawatan memuaskan

f. Terampil menggunakan alat

g. Terampil menenangkan pasien

h. Terampil mengajak pasien untuk mau dilakukan tindakan perawatan

i. Cepat memberikan obat bila diperlukan

j. Memberikan saran yang tepat
Berdasarkan hasil penelitian pada pasien yang pernah berkunjung dan kembali lagi berkunjung ke poli gigi Puskesmas Darussalam untuk menerima pelayanan kesehatan gigi dan mulut yang dilihat dari dimensi empati dan dimensi fisik seluruh pelayanan yang diterima oleh pasien sudah baik yakni pada dimensi empati, dokter mempunyai waktu untuk menanyakan keluhan, dokter menggunakan tutur sapa yg sopan, dokter menggunakan bahasa yang baik dan dimengerti oleh pasien, memberikan hasil pemariksaan gigi dengan jelas, memberitahukan tindakan perawatan $100 \%$. Pada dimensi fisik, kebersihan ruangan, kerapian ruang tunggu,kebersihan alat untuk tindakan perawatan, kondisi alat, dan kenyamanan diruang perawatan 100\%. Pada dimensi jaminan, dokter memberikan rasa aman kepada pasien sewaktu melakukan tindakan perawatan, pasien percaya atas tindakan perawatan yang dilakukan sesuai kebutuhan perawatan, dokter memberikan pelayanan secara menyeluruh dan tuntas, dokter memenuhi pelayanan yang telah dijanjikan, pasien puas terhadap pelayanan yang diberikan, karena dokter menjamin hasil yang baik, dokter memberikan kepastian akan kesembuhan pasien $100 \%$. Pada dimensi ketanggapan dokter memeriksa dengan teliti, dokter bekerja dengan tepat, dokter bekerja dengan aman, hasil kerja/perawatan memuaskan, cepat memberikan obat dan dokter memberikan saran yang tepat $100 \%$.

Sesuai persentase dari dimensi empati, dimensi fisik, dimensi jaminan, dan dimensi ketanggapan dapat dilihat dari hasil jawaban kuesioner oleh pasien bahwa pada kenyataannya pasien telah puas dengan pelayanan kesehatan gigi dan mulut di Puskesmas Darussalam.

Sehingga untuk pengolahan data yang diperoleh melalui penelitian ini diolah secara manual dan tidak dilakukan analisis bivariat dengan uji chi square.

Berdasarkan hasil penelitian terhadap pasien yang pernah berkunjung sebelumnya dan tidak kembali berkunjung ke poli gigi Puskesmas Darussalam untuk menerima pelayanan kesehatan gigi dan mulut yang dapat dilihat melalui dimensi empati, masih banyak pelayanan yang kurang memuaskan pasien karena dokter menerima dan menyapa pasien ramah 3,3\%, dokter menunjukkan ekspresi wajah yang lembut $36,6 \%$, dokter menggunakan tutur sapa yang sopan $63,3 \%$, dokter menggunakan bahasa yang dimengerti oleh pasien $53,3 \%$. Pada dimensi fisik pasien kurang puas dengan pelayanan kesehatan karena kondisi ruang perawatan yang kurang rapi $60 \%$, kebersihan alat yang digunakan untuk tindakan perawatan $40 \%$, alat yang tersedia dengan lengkap untuk tindakan perawatan $13,3 \%$, alat tersusun rapi $10 \%$, alat yang digunakan canggih 6,6\%, pasien nyaman di ruang perawatan $10 \%$. Pada dimensi jaminan pasien kurang puas dengan pelayanan kesehatan karena dokter memberikan rasa nyaman terhadap pasien ketika dilakukan perawatan $30 \%$, pasien tidak ragu atas perawatan yang diberikan $26,6 \%$, pasien bebas dari masalah kesehatan gigi setelah menerima perawatan $33,3 \%$, tidak adanya resiko yang timbul setelah menerima perawatan $46,6 \%$, dokter mampu menuntaskan masalah kesehatan gigi pasien 26,6\%, dokter memenuhi pelayanan yang dijanjikan sebelumnya $30 \%$, pasien puas 
atas pelayanan yang diterima $16,6 \%$, dokter menjamin hasil perawatan yang baik $20 \%$, dokter memberikan kepastian kesembuhan pasien atas masalah kesehatan giginya $16,6 \%$.

Tabel 5: Persentase Kepuasan Pasien Terhadap Pelayanan Kesehatan Gigi Dan Mulut Di Puskesmas Darussalam Pada Dimensi Empati

\begin{tabular}{ccccc}
\hline \multirow{2}{*}{$\begin{array}{c}\text { Dimensi } \\
\text { empati }\end{array}$} & $\begin{array}{c}\text { Pasien yang pernah } \\
\text { berkunjung dan } \\
\text { kembali }\end{array}$ & \multicolumn{2}{c}{$\begin{array}{c}\text { Pasien yang pernah } \\
\text { berkunjung dan } \\
\text { tidak kembali }\end{array}$} \\
\cline { 2 - 5 } & $\begin{array}{c}\text { Jumlah } \\
(\mathrm{n})\end{array}$ & $\begin{array}{c}\text { Persentase } \\
(\%)\end{array}$ & $\begin{array}{c}\text { Jumlah } \\
(\mathrm{n})\end{array}$ & $\begin{array}{c}\text { Persentase } \\
(\%)\end{array}$ \\
\hline Baik & 30 & 100 & 11 & 36,6 \\
Cukup & 0 & 0 & 12 & 40 \\
Kurang & 0 & 0 & 7 & 23,3 \\
\hline Jumlah & 30 & 100 & 30 & 100 \\
\hline
\end{tabular}

Berdasarkan Dimensi empati diperoleh pasien yang pernah berkunjung dan kembali berkunjung yang puas terhadap pelayanan kesehatan gigi dan mulut di Poli gigi Puskesmas Darussalam Medan dan dinyatakan baik dibanding kepuasan pasien yang pernah berkunjung sebelumnya dan tidak kembali berkunjung yaitu masingmasing $100 \%$ dan $36,6 \%$. Hasil penelitian terhadap dimensi empati, diperoleh perbedaan kepuasan pasien terhadap pelayanan kesehatan gigi dan mulut di Puskesmas Darussalam.

Tabel 6: Persentase Kepuasan Pasien Terhadap Pelayanan Kesehatan Gigi dan Mulut Di Puskesmas Darussalam Pada Dimensi Fisik

\begin{tabular}{ccccc}
\hline & $\begin{array}{c}\text { Pasien yang pernah } \\
\text { berkunjung } \\
\text { sebelumnya dan } \\
\text { Dimensi } \\
\text { fisik }\end{array}$ & $\begin{array}{c}\text { Pasien yang pernah } \\
\text { berkunjung } \\
\text { kembali }\end{array}$ & $\begin{array}{c}\text { sebelumnya dan tidak } \\
\text { kembali }\end{array}$ \\
\cline { 2 - 5 } & $\begin{array}{c}\text { Jumlah } \\
\text { (n) }\end{array}$ & $\begin{array}{c}\text { Persentase } \\
(\%)\end{array}$ & $\begin{array}{c}\text { Jumlah } \\
(\mathrm{n})\end{array}$ & $\begin{array}{c}\text { Persentase } \\
(\%)\end{array}$ \\
\hline Baik & 30 & 100 & 2 & 6,6 \\
Cukup & 0 & 0 & 20 & 66,6 \\
Kurang & 0 & 0 & 8 & 26,6 \\
\hline Jumlah & 30 & 100 & 30 & 100 \\
\hline
\end{tabular}

Berdasarkan Dimensi fisik, diperoleh pasien yang pernah berkunjung dan kembali berkunjung yang puas terhadap pelayanan kesehatan gigi dan mulut di poli gigi Puskesmas Darussalam Medan dan dinyatakan baik dibanding dengan kepuasan pasien yang pernah berkunjung sebelumnya dan tidak kembali berkunjung yaitu masing-masing $100 \%$ dan 6,6\%. Hasil analisis terhadap dimensi fisik diperoleh perbedaan kepuasan pasien terhadap pelayanan kesehatan gigi dan mulut di Puskesmas Darussalam.
Tabel 7: Persentase Kepuasan Pasien Terhadap Pelayanan Kesehatan Gigi dan Mulut Di Puskesmas Darussalam Pada Dimensi Jaminan

\begin{tabular}{|c|c|c|c|c|}
\hline \multirow[t]{2}{*}{$\begin{array}{l}\text { Dimensi } \\
\text { jaminan }\end{array}$} & \multicolumn{2}{|c|}{$\begin{array}{l}\text { Pasien yang pernah } \\
\text { berkunjung } \\
\text { sebelumnya dan } \\
\text { kembali } \\
\end{array}$} & \multicolumn{2}{|c|}{$\begin{array}{l}\text { Pasien yang pernah } \\
\text { berkunjung } \\
\text { sebelumnya dan tidak } \\
\text { kembali }\end{array}$} \\
\hline & $\begin{array}{c}\text { Jumlah } \\
\text { (n) }\end{array}$ & $\begin{array}{c}\text { Persentase } \\
(\%)\end{array}$ & $\begin{array}{c}\text { Jumlah } \\
\text { (n) }\end{array}$ & $\begin{array}{c}\text { Persentase } \\
(\%)\end{array}$ \\
\hline Baik & 30 & 100 & 0 & 0 \\
\hline Cukup & 0 & 0 & 6 & 20 \\
\hline Kurang & 0 & 0 & 24 & 80 \\
\hline Jumlah & 30 & 100 & 30 & 100 \\
\hline
\end{tabular}

Berdasarkan Dimensi jaminan, diperoleh pasien yang pernah berkunjung sebelumnya dan kembali berkunjung yang puas terhadap pelayanan kesehatan gigi dan mulut di poli gigi Puskesmas Darussalam Medan dan dinyatakan baik dibanding dengan kepuasan pasien yang pernah berkunjung dan tidak kembali berkunjung yaitu masing-masing $100 \%$ dan 0\%. Hasil analisis terhadap dimensi jaminan, diperoleh perbedaan kepuasan pasien terhadap pelayanan kesehatan gigi dan mulut di Puskesmas Darussalam.

Tabel 8: Persentase Kepuasan Pasien Terhadap Pelayanan Kesehatan Gigi dan Mulut Di Puskesmas Darussalam Pada Dimensi Ketanggapan

\begin{tabular}{ccccc}
\hline \multirow{2}{*}{$\begin{array}{c}\text { Dimensi } \\
\text { ketanggapan }\end{array}$} & $\begin{array}{c}\text { Pasien yang pernah } \\
\text { berkunjung } \\
\text { sebelumnya dan } \\
\text { kembali }\end{array}$ & $\begin{array}{c}\text { Pasien yang pernah } \\
\text { berkunjung sebelumnya } \\
\text { dan tidak kembali }\end{array}$ \\
\cline { 2 - 5 } & $\begin{array}{c}\text { Jumlah } \\
\text { (n) }\end{array}$ & $\begin{array}{c}\text { Persentase } \\
(\%)\end{array}$ & $\begin{array}{c}\text { Jumlah } \\
(\mathrm{n})\end{array}$ & $\begin{array}{c}\text { Persentase } \\
(\%)\end{array}$ \\
\hline Baik & 29 & 96,6 & 2 & 6,6 \\
cukup & 0 & 0 & 13 & 43,3 \\
Kurang & 1 & 3,3 & 15 & 50 \\
\hline Jumlah & 30 & 100 & 30 & 100 \\
\hline
\end{tabular}

Berdasarkan Dimensi ketanggapan diperoleh pasien yang pernah berkunjung dan kembali lagi berkunjung yang puas terhadap pelayanan kesehatan gigi dan mulut di Poli gigi Puskesmas Darussalam Medan dan dinyatakan baik dibanding dengan kepuasan pasien yang pernah berkunjung dan tidak kembali lagi berkunjung yaitu masing-masing 96,\% dan 6,6\%. Hasil analisis bivariat terhadap dimensi ketanggapan diperoleh perbedaan kepuasan pasien terhadap pelayanan kesehatan gigi dan mulut di Puskesmas Darussalam

\section{Pembahasan}

Karakteristik pasien yang datang berkunjung ke poli gigi Puskesmas Darussalam bila dilihat dari segi umur pada pasien yang pernah berkunjung dan kembali berkunjung dan pasien yang pernah berkunjung dan tidak kembali berkunjung lebih banyak berumur 17-27 tahun. Hasil penelitian Situmorang, N (2004) di dua kecamatan kota Medan diperoleh prevalensi karies (decay) tertinggi pada kelompok umur 17-27 tahun. 
Berdasarkan jenis kelamin responden perempuan lebih banyak dibandingkan laki-laki. Budiarto (2003) menyatakan, secara umum angka morbiditas perempuan lebih tinggi dan cenderung lebih merasakan sakit dibandingkan laki-laki. Hal ini didukung dengan hasil penelitian Situmorang, N (2004) bahwa perempuan lebih sering mengalami keluhan kualitas hidup. Menurut Gondhoyoewono dan Wardani (1987), bahwa perempuan lebih memperhatikan keindahan, kebersihan, dan penampilan diri, sehingga mengupayakan mengatasi masalah yang timbul pada kesehatan gigi dan mulutnya.

Kepuasan pasien yang pernah berkunjung dan kembali lagi berkunjung dan pasien yang pernah berkunjung dan tidak kembali berkunjung dilihat dari dimensi empati, dimensi jaminan, dan dimensi ketanggapan yaitu kurangnya kepuasan pasien karena sambutan dokter yang kurang ramah, ekspresi wajah dokter yang tidak lembut, tutur sapa yang kurang sopan dan bahasa yang digunakan oleh dokter tidak dimengerti oleh pasien, dokter tidak memberikan rasa nyaman sewaktu melakukan tindakan perawatan terhadap pasien, pasien ragu atas tindakan dokter, adanya resiko yang muncul setelah menerima tindakan, dokter tidak memenuhi pelayanan yang dijanjikan,dokter tidak memeriksa kondisi kesehatan gigi dengan teliti, dokter tidak bekerja dengan cepat, dokter tidak menjamin hasil yang baik, hasil perawatan tidak memuaskan dan dokter tidak terampil menenangkan pasien sewaktu dilakukan perawatan.

Hasil penelitian Matteo dan Nicola (1982) menyatakan bahwa kepuasan pasien yang paling dominan disebabkan kerena adanya hubungan interpersonal yang baik antara dokter gigi dengan pasien. Adanya kedekatan menyebabkan pasien merasa bebas menyampaikan keluhan dan meminta saran terhadap penyakit yang diderita dan dari perhatian yang diberikan oleh dokter gigi akan memberikan kepuasan kepada pasien.

Kepuasan pasien pada pasien yang pernah berkunjung dan kembali lagi berkunjung dengan pasien yang pernah berkunjung dan tidak kembali lagi berkunjung dilihat dari dimensi fisik yaitu peralatan yang tidak bersih dan peralatan yang tidak lengkap sehingga menghambat kebutuhan perawatan gigi dan mulut pasien.

Hasil penelitian Gunawan (1992) menunjukkan selain prosedur pelayanan yang efisien dan ditunjang dengan fasilitas/sarana yang baik maka keterampilan dan kemampuan pemberi pelayanan merupakan hal utama yang perlu dipertimbangkan dalam suatu pelayanan.

Pelayanan dokter gigi yang kurang baik akan berdampak pada ketidakpuasan pasien yang berkunjung. Hal ini dapat dilihat dari dokter yang kurang ramah dalam melayani pasien, selain itu peralatan yang tidak lengkap mengakibatkan berkurangnya mutu pelayanan kesehatan yang berdampak pada kunjungan.

Hal ini mungkin dapat ditanggulangi dengan adanya pendekatan dokter gigi sebagai pemberi palayanan kesehatan dan dengan menyediakan peralatan yang lengkap dan baik untuk digunakan, sehingga tidak mengurangi tingkat kepuasan pasien dan pasien tetap melakukan kunjungan ke Poli gigi Puskesmas Darussalam.

\section{Kesimpulan}

1. Karakteristik pasien yang datang ke poli gigi Puskesmas Darussalam relatif sama, dengan distribusi terbesar yaitu umur 17-27, jenis kelamin perempuan.

2. Hasil penelitian diperoleh adanya perbedaan kepuasan pasien yang pernah berkunjung dan kembali dengan kepuasan pasien yang pernah berkunjung dan tidak kembali ke pelayanan kesehatan gigi dan mulut yaitu ke poli gigi Puskesmas Darussalam. Perbedaan kepuasan tersebut dapat dilihat dari dimensi empati $100 \%$ dan $6,6 \%$, dimensi fisik $100 \%$ dan $0 \%$, dimensi jaminan 100\% dan 0\%, dan dimensi ketanggapan $96,6 \%$ dan $6,6 \%$.

3. Pada kenyataannya pasien yang pernah berkunjung ke poli gigi Puskesmas Darussalam sudah puas dengan pelayanan kesehatan gigi dan mulut yang diberikan dan hipotesis ditolak, hanya perlu peningkatan mutu pelayanan kesehatan gigi dan mulut sehingga kunjungan pasien semakin meningkat.

\section{Saran}

1. Kepada Puskesmas Darussalam hendaknya berupaya mengatasi penyebab ketidakpuasan pasien terhadap pelayanan kesehatan gigi dan mulut yaitu dengan meninjau kembali dimensi empati, dimensi fisik, dimensi jaminan, dan dimensi ketanggapan. Pengadaan alat yang lengkap sebagai sarana utama memberikan pelayanan kesehatan gigi dan mulut kepada pasien sebagai upaya meningkatkan mutu pelayanan kesehatan gigi dan mulut di Puskesmas Darussalam.

2. Kepada profesi dokter gigi dalam pemberian pelayanan kesehatan gigi dan mulut agar senantiasa memperhatikan dimensi-dimensi yang dapat mempengaruhi kepuasan pasien, antara lain melalui dimensi empati, dimensi fisik, dimensi jaminan, dan dimensi ketanggapan.

\section{Daftar Pustaka}

Budiarto, E, 2003, Pengantar Epidemiologi, Jakarta, Binarupa Aksara.

Departemen Kesehatan RI, 2003, Sistem Kesehatan Nasional, Jakarta.

Departemen Kesehatan RI, 2004, Sistem Kesehatan Nasional, Jakarta.

Gondhoyoewono, T, 1997, Peranan Psikologi dan Komunikasi Pada Program Kesehatan Gigi Dan mulut, Majalah Ilmiah Kedokteran Gigi FKG Usakti.

Gunawan, N, 1992, Hubungan Kepuasan Pasien / Keluarga Dengan Upaya Pelayanan Rawat Inap husada, Tesis Pasca Sarjana UI, Jakarta.

Idawani, 2001, Hubungan Antar Mutu dan Cakupan Pelayanan Unit dan Puskesmas di Provinsi Banda Aceh. 
Kuswadji, S, 1996, Penjaminan Mutu Praktek Dokter Keluarga, Jakarta, Widya Medika.

Lumenta, B, Pasien Citra, Peran dan Perilaku, Penerbit Konisius, Yogyakarta.

Notoadmodjo, S, 2010, Metodologi Penelitian Kesehatan, Jakarta, Rineka Cipta.

Nuraskin, A.C ; Hamsar, A ; Manurung, K ; 2015, Bahan Ajar Karya Tulis Ilmiah, USU. Press.

Pohan, S, 2007, Jaminan Mutu Layanan Kesehatan, Cetakan I, Jakarta, Penerbit Buku Kedokteran EGC.
Ria, N, 2005, Analisis Kepuasan Pasien Terhadap Pelayanan Kesehatan Gigi Di Rumah Sakit Umum Dr. Pringadi Medan dan Rumah Sakit Umum Tembakau Deli PTP Nusantara 2 Medan, Tesis, Program Magister Administrasi dan Kebijakan Kesehatan, USU.

Situmorang, N, 2004, Dampak Karies Gigi dan Penyakit Periodontal Terhadap Kualitas Hidup, Jakarta, Desertasi.

Undang Undang Kesehatan, 2003, Jakarta. 